\title{
USUCAPIÃO ESPECIAL : \\ Características do imóvel usucapiendo em face da Constituição Federal de 1988
}

\author{
Giselda Maria Femandes Novaes Hironaka \\ Professora Doutora da Faculdade de Direito da USP \\ Professora Adjunta da Faculdade de Direito Mackenzie
}

\begin{abstract}
Resumo:
À luz do Direito Agrário, o presente trabalho visa converter o tratamento legislativo-doutrinário do instituto do Usucapião Especial à nova dimensão constitucional (C.F./1988). Ao lado das demais modalidades de usucapião (ordinário e extraordinário), este, o especial, é a modalidade agrária de prescrição aquisitiva, caracterizada por também especial posse, já que não se contentou o legislador agrário com a simples e comum posse, mas acrescentou-lhe dois importantes requisitos, quais sejam, cultura efetiva e morada habitual. A atual Constituição Federal altera a feição do instituto, embora mantenha em vigor a legislação ordinária anterior (Lei $\mathrm{n}^{0}$ 6.969/81); mas revoga, contudo, alguns dispositivos, que perecem em face da nova ordem constitucional.
\end{abstract}

\begin{abstract}
:
Under Agrarian Law, the objective of this work is to convert the doctrinairelegislative treatment of the institute of special prescription to the new constitutional dimension (C.F./1988). Besides the other modalities of prescription (ordinary and extraordinary), this one, the special prescription, is the agrarian modality of acquisitive prescription, characterized also by special ownership, the agrarian legislator not being contented with simple and common ownership, but adding to important requirements, effective cultivation and habitual dwelling. The present Federal Constitution changes the appearance of the institute keeping in force, however, the previous ordinary legislation (Law $n^{\circ} 6.969 / 81$ ) but revoking some of the provisions, that disappear with the new constitutional order.
\end{abstract}

O usucapião especial, disciplinado pela Lei no 6.969/81, instituto típico e dos mais importantes do Direito Agrário, revela sua essência ao expor a relevante função social que desempenha.

Assim como as demais modalidades de usucapião, o especial se traduz como sendo um dos modos originários de aquisição da propriedade, a consolidar-se pela posse continuada, por um certo lapso de tempo, de imóvel 
rural, onde aquele que cstá usucapindo, realize o seu trabalho pessoal destinado à dinamização da atividade agrária, visando a consecução produtiva.

Indubitavelmente, é nesse desempenho laboral que repousa a justificativa desta modalidade de usucapião, já que o legislador agrário não se satisfaz com a simples posse, mas exige que o usucapiente efetivamente desenvolva atividade específica do labor agrário (trabalho produtivo), bem como ocupe o imóvel, nele estabelecendo sua morada (morada habitual).

Estes trabalho produtivo e morada habitual - são os requisitos da chamada "posse agrária". que difere da posse comum, pelo fato da produtividade e da pessoalidade do ato agrário, impregnando-se, como tudo o mais que compõe o conteúdo do Direito Agrário, da milenar função social da propriedade. E esta é a posse ad usucapionem da espécie em exame, isto é, a posse hábil para gerar o usucapião especial.

O que mais marca a diferença entre esta e as demais espécies de usucapião - o ordinário e o extraordinário além da posse diferenciada, é o lapso temporal menor para que a aquisição se concretize, já que bastam cinco anos ininterruptos e sem oposição.

Este instituto beneficiará o rurícola que não for proprietário rural nem urbano e recairá somente sobre as terras rurais particulares.

Neste passo, é de se anotar as inovações trazidas pela Constituição Federal de 1988, em sede de usucapião especial, numa menção paralela àqueles aspectos que não sofreram modificação pelo novo texto.

A Carta Magna de 1988, volta a mencioná-lo, após o interregno constitucional criado pela Constituição Federal de 1967 e Emenda Constitucional de 1969, que nada dispuseram a respeito, em razão, com certeza, de já haver sido a matéria tratada pelo Estatuto da Terra em 1964 (art. 98).

Em 1981, como já se disse, o assunto foi plenamente cuidado pela Lei ${ }^{\circ}{ }^{\circ}$ 6.969 .

O art. 191 e § único da Constituição Federal (1988), então retomando no seu bojo o tema, inserem modificações à regulamentação anterior derivada da Lei $\mathrm{n}^{\mathrm{o}} 6.969 / 81$.

Mas também, já se o mencionou, conservou inalterados certos requisitos ou certos pressupostos, tal como já se encontravam enunciados pela legislação anterior. 
Senão vejamos:

De um lado manteve o peculiar prazo de cinco anos, lapso temporal exíguo, se comparado com as demais modalidades de prescrição aquisitiva, como o usucapião ordinário (dez ou quinze anos) e o usucapião extraordinário (vinte anos), mas que se encontra em perfeita harmonia com o modo próprio do Direito Agrário, já que determina o cultivo efetivo e exige morada habitual.

Por isso, apresenta-se como modalidade "humanizada" e revestida da verdadeira função social que marca e norteia toda a ciência jus-agrarista. Tratase de modalidade que valoriza e recompensa aquele que destina sua atividade laboral à produção do solo e efetivamente o fecunda.

Não seria razoável imaginar que tal recompensa viesse só após um lapso temporal de dez ou quinze anos. A quebra dos ideais de justiça social e dos princípios que embasam o Direito Agrário far-se-ia sentir e a conseqüência seria o desestímulo do rurícola.

Por isso, andou bem o legislador constitucional ao confirmar o prazo de cinco anos, abonando e ratificando os trabalhos de juristas que antecederam a promulgação da Lei $\mathrm{n}^{\mathrm{o}}$ 6.969/81, trabalhos estes todos desenvolvidos no empenho de abreviar o requisito-tempo para o usucapião especial.

Quanto à pessoa do usucapiente, não trouxe a atual Constituição nenhuma modificação essencial, firmando os pressupostos no fato de dever ser ele, o que pretende usucapir, pessoa física, brasileiro ou estrangeiro (este sob as restrições da Lei $n^{\circ}$ 5.709/71), homem ou mulher, desde que não seja proprietário, quer urbano quer rural.

No que diz respeito à posse hábil para gerar tal modalidade aquisitiva de propriedade, e além do que já se mencionou sobre o fato de ser uma posse diferenciada (verdadeira posse agrária, poder-se-ia dizer), recorde-se que esta posse deve ser contínua e sem oposição, nem reconhecimento de domínio alheio.

O usucapiente a exercerá com animus domini e a possibilidade da junção de posse por transmissão inter vivos estará completamente fora de cogitação.

Efetivamente se trata de uma posse especial, uma posse ad usucapionem diferenciada, para uma modalidade diferenciada de usucapião.

Com certeza, as modificações primordiais derivadas do texto constitucional, promulgado em outubro de 1988, decorrem do aspecto relacionado ao objeto do usucapião especial. 
Assim é que, hoje, o campo de incidência desta modalidade, restringe-se, apenas, aos imóveis rurais particulares, já que a Constituição determinou que "os imóveis públicos não serão adquiridos por usucapiāo" (§ único, art. 191).

Desta forma, afastou-se a incidência de usucapião especial sobre terras devolutas, espécie do gênero bens públicos, que outrora (Lei $\mathrm{n}^{\mathfrak{Q}}$ 6.969/81), encontravam-se elencadas como objeto de usucapião especial, ao lado das terras particulares.

Dois Decretos regulamentaram esta matéria:

- o Decreto no 87.040/82, que especificou as áreas indispensáveis à segurança nacional insuscetíveis de usucapião especial, excluindo assim certas terras devolutas que ocupassem tais características;

- o Decreto $\mathrm{n}^{\mathrm{o}}$ 87.620/82, que dispôs sobre o procedimento administrativo para o reconhecimento da aquisição, por usucapião especial, de imóveis rurais compreendidos como terras devolutas.

Observe-se que tal regulamentação já era limitadora, como não podia mesmo deixar de ser, permitindo a exposição das terras devolutas como possível alvo de aquisição por usucapião, de modo bastante restrito e seguro.

Incompreende-se, por isso, a exclusão das terras devolutas da categoria daqueles imóveis rurais que poderiam ser usucapidos.

Recolheu benefícios, tão arduamente conquistados, o legislador constitucional ao rurícola que pretendesse usucapir imóvel rural em terras devolutas. Com toda a certeza, tal exclusão acarretará, inevitavelmente, a retração do desempenho laboral produtivo em tais terras públicas.

Este fato gerará, em conseqüência, o desestímulo ao povoamento e desenvolvimento econômico-social de regiões via de regra com baixa densidade demográfica e carenteś de recursos humanos, produtivos e econômicos.

Apresenta-se a circunstância, talvez, como mais um daqueles odiosos entraves ao desenvolvimento do meio rural, através da estabilização do seu setor primário.

Por outro lado, como que numa "permuta legislativa", a Constituição, conservando as terras rurais particulares na mira da aquisição prescritiva em exame, aumentou-lhes a área, dobrando o número de hectares, isto é, permitindo a aquisição de área rural de até 50 hectares. A legislação anterior alterada (Lei $\mathbf{n}^{\mathrm{o}}$ 6.969/81) dispunha que tal área não deveria exceder de 25 hectares, 
afirmando, no $\S$ único do art. $1^{2}$, que prevaleceria a área do módulo rural aplicável à espécie, na forma da legislação específica, sc aquele fosse superior a 25 hectares. Este acréscimo, de 25 hectares para 50 hectares, não terá tido o efeito de revogar - no nosso modo de entender o §único do art. $1^{o}$ da citada Lei, de tal sorte que aquela possibilidade de se usucapir área maior que 50 hectares, ainda prevalece, desde que o módulo ali então aplicável seja maior que a mencionada metragem.

Por fim, registre-se que a mesma sorte não tiveram os $\S \S 2^{\circ}, 3^{\circ}$ e $4^{\circ}$ do art. $4^{2}$ da Lei $\mathrm{n}^{\mathrm{O}}$ 6.969/81, bem como o Decreto $\mathrm{n}^{\mathrm{o}}$ 87.620/82, que foram revogados pelo novo•texto constitucional, já que esses $\S \S$ e este Decreto regulavam o procedimento administrativo para o reconhecimento de usucapião de terras devolutas.

Assim sendo, hoje, resta reservado àquele que pretenda a declaração de usucapião, tão apenas o procedimento judicial, já que, atualmente, o usucapião especial recai exclusivamente sobre terras rurais particulares.

Dedico este estudo a Antonio Junqueira de Azevedo, que me emocionou ao dizer: o "nosso" Direito Agrário. 